\title{
ЭТНОПСИХИАТРИЯ
}

\author{
УДК 616.89-008.1:2-486.3:331.556:351.778:364-785.14
}

Для цитирования: Артемьев И.А., Владимирова С.В. Адаптация и приживаемость мигрантов с психическими расстройствами - диалектическое единство. Сибирский вестник психиатрии и наркологии. 2019; 1 (102): 99 107. https://doi.org/10.26617/1810-3111-2019-1(102)-99-107

\section{Адаптация и приживаемость мигрантов с психическими расстройствами - диалектическое единство}

\section{Артемьев И.А., Владимирова С.В.}

НИИ психического здоровья, Томский нацииональньй исследовательский медицинский центр

Российской академии наук

Россия, 634014, Томск, ул. Алеутская, 4

\section{PEЗЮME}

В статье рассматриваются различные функции миграции. Авторами постулируется медицинская парадигма миграции населения как направленного потока здоровья, за счет которого и происходит освоение новых территорий и развитие уже сложившихся производств. Определены роль и место адаптационных процессов в когорте мигрантов с психическими расстройствами. По материалам исследования утверждается, что закрепление мигрантов в местах их вселения - «приживаемость» - находится в диалектическом единстве с их адаптацией.

Ключевые слова: миграция населения, психические расстройства, адаптация, приживаемость, диалектическое единство.

\section{ВВЕДЕНИЕ}

Термин «миграция населения» включает несколько видов данного понятия: внутренняя, внешняя, эмиграция на постоянное место жительства, временная, долгосрочная, маятниковая, эпизодическая приграничная, обратная, кочевничество, паломничество, а также беженцы и вынужденные переселенцы. Мотивы (причины) миграции могут иметь широкий спектр: экономические, политические, социально-бытовые, природные. В последнее время появился термин «потенциальная миграция», формирование «потенциальных мигрантов», т.е. людей, склонных на определенных условиях к участию в миграционных процессах. Миграции имманентны специфические, определенные функции. Так, экономическая функция миграции заключается в хозяйственном освоении земли, развитии производительных сил, соединении территориального распределения природных ресурсов и средств производства с рабочей силой. В этом контексте миграция выступает как источник рынка труда. Социальная её роль связана с реализацией потребностей населения в жилье, работе и социальной мобильностью, под которой понимается мобильность по уровню образования, рост социального статуса мигранта и его семьи. Миграция населения представляет собой один из факто- ров его социально-культурального и экономического развития, затрагивая также глубинные популяционно-этнические детерминанты [1].

Миграция выполняет функцию перераспределения рабочей силы на рынке труда, т.е. миграционные потоки формируются в соответствии с потребностью в трудовых ресурсах определенных территорий. Но пространственное (географическое) перемещение населения отражает только внешнюю видимую сторону феномена, изучение которого составляет предмет немедицинских наук (экономики, географии, социологии и т.д.).

К мигрирующему населению предъявляется непременное требование, чтобы оно обладало особым качеством - было в высокой степени трудоспособным, по крайней мере, по этой характеристике прибывающее население должно быть не худшего качества, чем коренное. Участвуя в процессе производства, своим физическим или интеллектуальным трудом производя товары и услуги, человек расходует свою энергию, аккумулированную в его здоровье, т.е. в конечном счете всё производится за счет здоровья. Таким образом, медицинская парадигма миграции населения - это перемещение, перераспределение здоровья. В этом контексте миграция населения - направленный поток здоровья, за счет которого и происходит 
освоение новых территорий и развитие уже сложившихся производств. Хотя необходимо иметь в виду, что само понятие «здоровье» имеет в литературе около 40 определений [2].

Проблема миграции населения особенно актуальна для Сибири, где она представляет одну из наиболее ярких специфических черт региона. Трудно не согласиться с прогнозными расчетами В.П. Казначеева, который считает, что у населения этого региона, если учитывать критерии продолжительности жизни, психического и биологического здоровья в лучшем случае хватит до 2020-2025 гг. Оно будет переработано догматическим, технократическим комплексом с уничтожением не только человека, но и природного комплекса [3, 4]. Оказалось, что миграция благодаря своей селективной функции, заключающейся в изменении качественного состава населения, оказывает неоднозначное влияние на распространенность психических заболеваний и алкоголизма в популяциях мест иммиграции.

\section{ЦЕЛЬ ИССЛЕДОВАНИЯ}

Показать, что психические расстройства у людей, сменивших место первоначального проживания, могут возникать в разное время после их переселения. Результирующей функцией адаптации является длительность проживания в местах вселения - приживаемость мигрантов.

\section{МАТЕРИАЛЫ И МЕТОДЫ ИССЛЕДОВАНИЯ}

Нами проведены исследования психического здоровья населения интенсивно осваиваемых регионов Тюменского Севера и традиционных регионов южной части Восточной Сибири, где миграционные потоки носят традиционный характер. Рассмотрены процессы миграции больных с психическими расстройствами в города Сургут, Петропавловск-Камчатский и Кызыл. По европейским масштабам территориальные перемещения в широтном и меридиональном направлениях соответствуют Лондон - НьюЙорк, Лондон - Афины.

Были изучены корреляционные связи распространенности психических заболеваний, алкоголизма с миграционными параметрами (миграционным приростом, результативностью миграции и её оборотом) на материале городского населения всех 18 административных территорий Сибири. Обнаружено, что на территориях, имеющих положительный миграционный прирост, корреляции параметров миграции и распространенности психических заболеваний имеют положительный знак, при алкоголизме эти взаимосвязи не достоверны.
Поскольку оба процесса - увеличение населения и накопление психически больных протекают однонаправленно, то мигрирующее население может способствовать приросту психически больных. В то же время повсеместное увеличение алкоголизма не связано с более высоким его уровнем в прибывающем населении.

Совершенно иная картина складывается на большинстве других 14 территорий, где происходит замедление миграционного прироста. Здесь статистически значимые взаимосвязи миграции с уровнем распространенности психических заболеваний и алкоголизма, как правило, отрицательны.

Динамика рассматриваемых нами классов заболеваний отражает накопление как психически больных, так и страдающих алкоголизмом. На 14 территориях это происходит на фоне относительного сокращения прибывающего населения и результативности миграции. Таким образом, отрицательный характер корреляционных связей при относительном сокращении миграционного прироста может свидетельствовать, что миграции sui generis не влияет на рост указанной патологии в населении, а ее селективная функция на популяционном уровне проявляется в том, что сама она может рассматриваться как один из феноменов метапрофилактики.

\section{РЕЗУЛЬТАТЫ И ИХ ОБСУЖДЕНИЕ}

Имеет значение фоновый уровень зарегистрированной болезненности стационарного населения, а также характер миграционных связей (внутриобластной, межрегиональной). На примере быстро развивающегося города Тюменского Севера, где население за рассматриваемый период возросло в 1,5 раза, и одного из городов Южной Сибири - Кызыла, в котором население за тот же период увеличилось на $10 \%$, нами обнаружено, что вновь формирующаяся северная городская популяция имеет более низкие частоты нервно-психических расстройств, нежели южная. Уровень этой патологии в ней превосходит аналогичные значения для северной выборки в 3,8 раза, по собственно психозам - в 4,5 раза, по непсихотическим психическим расстройствам - в 3,4 раза. Вместе с тем в обоих случаях наличие больных жестко связано со среднегодовой численностью населения. Следовательно, параллельно с формированием населения северного города происходит увеличение количества больных в нём, в отличие от стационарной городской популяции, где эта величина остается стабильной. 
Однако механический прирост населения последнего неоднозначно связан с уровнем больных психозами и непсихотическими расстройствами, эта связь имеет разнонаправленные значения, т.е. иммигрирующее население привносит в популяцию южного города больных с психотическими формами заболеваний и олигофренией, а больные с непсихотическими заболеваниями (неврозами и психопатиями) в ближайшие сроки не становятся объектами внимания психиатрической службы. Для северного города миграционный прирост и распространенность психических заболеваний находятся в противоположных фазах: первый затихает, второй прогрессирует.

Таким образом, взаимосвязь миграционного прироста населения с уровнем распространенности психических заболеваний неоднозначна не только для различных городских популяций, но и для психотических и непсихотических их форм.

Интенсивность миграции сама по себе не является обстоятельством, приводящим к «самоочищению» населения, «вымыванию» лиц, нуждающихся в психиатрической или наркологической помощи. Так, в район интенсивного промышленного освоения г. Сургут прибыло здоровыми 93\% от общего количества больных шизофренией, а в традиционный г. Кызыл 72\%. В течение первых 5 лет проживания в обоих регионах заболело более половины от всего количества лиц, состоящих на диспансерном учете. В последующее пятилетие темп заболеваемости был достоверно ниже в субпопуляции традиционного региона. В районах нового хозяйственного освоения с интенсивным заселением частота алкоголизма жестко связана с ростом населения, тогда как в сформировавшихся популяциях при наличии ограниченных миграционных связей и исторически сложившемся уровне алкоголизма увеличение населения не приводит к росту частоты последнего. В то же время динамика миграционного прироста однозначно (отрицательно) связана с показателями распространенности алкоголизма: при затухающем механическом приросте они увеличиваются и, наоборот, относительная стабильность указанного прироста не ведет к возрастанию частоты алкоголизма.

Таким образом, миграционные потоки в районы нового промышленного освоения способствуют минимизации частотного уровня распространённости психических заболеваний и алкоголизма, в то время как в традиционных такой взаимосвязи не обнаружено. Прибывающее население способствует «оздоровлению» мест вселения, если судить по приведенным выше показателям. Однако в дальнейшем происходит накопление нервно-психической патологии и, соответственно, выравнивание с уровнем традиционных регионов. Следовательно, перемещение населения - это, прежде всего, миграция здоровья на рынке труда. Сибирь в этом отношении находится в чрезвычайно невыгодней ситуации.

Естественно, что каждому виду миграции в соответствии с мотивами переезда должен соответствовать и определенный эквивалент адаптации. В онлайн-словаре определений, значений и произношения слов английского языка Merriam-Webster https://www.merriamwebster.com/dictionary/adaptation приводится подробное определение этого понятия, включающее как биологические, так и социальные его аспекты.

Так, Lucken Kristen (2012) [5] в своей работе постулирует, что адаптация мигрантов относится к процессам, в результате которых приезжие приспосабливаются и интегрируются социально, экономически и политически в рамках принимающего общества. Такие факторы, как этническая принадлежность, раса, гендер, уровень образования, приносящие прибыль навыки и умение, религиозная принадлежность и языковая компетентность, могут воздействовать на легкость, с которой мигранты приспосабливаются к новой культурной и социальной системе. Отклики принимающего общества на запрос приезжих, включая желание и способность нации предложить гражданство, работу, образование, жилье и политическое представительство, являются важными аспектами динамики интеграции мигрантов. Дополнительно факторы притягивания и выталкивания, движущие миграцию, также играют роль в приспособлении мигрантов к новому месту действия. Такие термины, как ассимиляция (уподобление), аккультурация (заимствование черт чужой культуры), инкорпорация (встраивание, включение, присоединение, смешивание, слияние) и интеграция, используются для описания различных путей, с помощью которых приезжие приспосабливаются и поглощаются экономикой, политической системой и социальной сферой принимающей нации.

В объемном литературном обзоре А.А. Овчинников, А.Н. Султанова, А.С. Лазурина, Т.Ю. Сычева (2018) [6], признают, что от 
успешности процесса адаптации зависит качество дальнейшей жизни, а во время приспособления к новой окружающей среде мигранты встречаются с проблемами как социального, так и психологического характера.

В коллективных исследованиях сибирские авторы [7, 8] приводят обширные сведения о психологической адаптации как об очень важном процессе, касающемся здоровья мигрантов, так как исследования, проведенные ранее, показывают, что иммигранты в большей степени страдают от ухудшения психического здоровья и от эмоциональных расстройств, нежели от проблем с местным населением.

Авторы разделяют позицию F. Rudmin [9] (цит. по Овчинников А.А., Султанова А.Н., Лазурина А.С., Сычева Т.Ю., 2016), который как составной элемент адаптации рассматривает аккультурацию, определяя её как процесс культурного обучения человека, который происходит при адаптации к чужой, новой культуре.

Исследователи в области этнопсихологических проблем считают, что выбор определенной модели аккультурации зависит от ряда факторов. При этом выделяются факторы двух уровней: микросоциальные и макросоциальные. J.W. Berry [10] предложил категорическую модель аккультурации, основанную на двух измерениях: первое измерение относится к той степени, в которой культура происхождения предпочитается человеком, второе - к той степени, в которой предпочитается новая принимающая культура. На основе взаимодействия между этими двумя измерениями были выделены четыре модели аккультурации: разделение, ассимиляция, интеграция и маргинализация.

C.S. Ward [11] предложил альтернативную модель. В ней рассматривается ряд переменных, которые имеют значение в процессе аккультурации: личные факторы (причины миграции, культурная самобытность, владение языком, стратегии аккультурации), ситуационные факторы (культурная дистанция, социальная поддержка, продолжительность контакта с иной средой).

Классические исследования характеризуют аккультурацию как однонаправленный линейный процесс. В ходе такого процесса человек адаптируется к нормам, традициям новой культуры, которая его принимает. Разными исследователями этой проблемы выделяются десятки факторов, которые в той или иной мере влияют на психологическое состояние и уровень адаптации мигрантов в новой культурной среде.
Психотические нарушения у мигрантов авторы рассматривают, используя литературные данные, как следствие дезадаптации. Известно, что миграция имеет ряд негативных последствий для людей, оказавшихся в новой чужеродной культуре. К негативным последствиям относятся, в том числе, и психические расстройства непсихотического уровня. Психоз одно из следствий дезадаптации мигрантов. Связь между психозами и миграцией была подтверждена более чем в 20 исследованиях и 2 метаанализах. Был сделан вывод, что риск появления психоза напрямую связан с различными социальными факторами, а не с выборочной миграцией людей, которые имеют генетическую предрасположенность. Все ранее проведенные исследования продемонстрировали явные различия во встречаемости и распространенности такого нарушения, как психоз, среди разных групп мигрантов. Следует отметить, что данный механизм недостаточно изучен, несмотря на то что актуальность этой проблемы с каждым днем расширяется в среде как этнопсихологов, так и этнопсихиатров $[12,13,14]$.

Авторы представили как в рассматриваемом обзоре, так и в ряде других своих работ глубокий анализ приспособления людей к новым для них условиям, оставаясь в рамках категории «адаптация», освещая ее различные аспекты.

В русском переселенческом движении еще co времен XIX века вошел в обиход термин «приживаемость», понимаемый как заключительная фаза миграционного процесса. Под приживаемостью понимается переход новоселов в состав постоянного населения на новом месте (Переведенцев В.И., 1975) [15].

«Приживаемость» характеризует вполне определенное социальное явление. Этот термин является порождением русского переселенческого движения. Не случайно термин «приживаемость» не имеет синонимов в западноевропейских языках. Вероятно, в западноевропейской литературе процесс приживаемости стал характеризоваться термином «адаптация» (Алаев Э.Б., 1983) [16]. Между тем следует согласиться с авторами, которые считают, что понятия «приживаемость» и «адаптация» имеют различия. Приживаемость - это явление, характеризующее переход новоселов в состав старожилов и, стало быть, в состав постоянного населения района вселения. Это не только процесс приспособления человека к новым условиям жизни, но и приспособление условий жизни к потребностям человека, т.е. приживаемость - 
объективный социальный процесс изменения сложившегося образа жизни посредством совершенствования новой социальной среды через социальную деятельность, формирующую потребности, отвечающие целям гармоничного развития (Кокарев Е.М., 1981) [17]. Не вдаваясь в детали дискуссии по поводу адекватности указанных терминов, следует лишь указать, что приживаемость включает в себя два компонента. Первым из этих элементов является адаптация - социальная и биологическая - к природным, экологическим, этнографическим, демографическим и прочим условиям. Второй составляющей является приспособление этих условий к своим потребностям, что бывает более важным. Хотя понятие «приживаемость» относится к такой категории населения, как «новосел», тем не менее рассмотрение этого процесса не может происходить вне контекста с такой категорией, как «старожил». По существу, миграция населения представляет собой многостадийный процесс, завершающая стадия которого наступает с момента вселения мигранта в новый для него район. С этого времени мигрант становится новоселом, для которого наступает период вживаемости в районе вселения новосела (Рыбаковский Л.Л., 1990) [18].

Миграция людей при наличии у них психических расстройств - явление повсеместное, несмотря на декретированные ограничения для этой категории переселенцев, принятые в Сургуте. Однако их количество в общем числе переселенцев в рассматриваемых городах позволило установить, что эта величина определяется не столько особенностями миграционных процессов, сколько соотношением внутриобластных и межрегиональных (межтерриториальных) перемещений. Так, мигранты, прибывшие больными в Сургут и ПетропавловскКамчатский, составили 9,07 $\pm 1,1 \%$ и $8,97 \pm 0,8 \%$ $(\mathrm{p}>0,05)$. Аналогичная картина характерна также и в отношении заболеваний, т.е. больные с психотическими расстройствами (в том числе шизофренией) и непсихотическими психическими заболеваниями (включая пограничные психические состояния) в Сургут и Петропавловск-Камчатский прибыли примерно в одинаковых численных пропорциях, в отличие от доли прибывших в Кызыл, где эта категория составила по отдельным нозологическим группам от 1/3 до 1/4 всей популяции.

Совершенно по-другому выглядит характер распределения больных, которые заболели в течение первых трех лет после приезда («но- воселы»). В Сургуте, например, в течение указанного срока заболело 26,87 $\pm 1,7 \%(\mathrm{p}<0,05)$ от общего количества всех больных, состоящих на диспансерном учете на контрольный срок. В то время как в других городах эта величина составила соответственно $17,57 \pm 1,7 \%$ и $14,37 \pm 1,0 \%$ $(p>0,05)$. Больные психозами и шизофренией зеркально отражают ситуацию, описанную для всех форм психических заболеваний: их удельный вес в Сургуте $(24,47 \pm 4,4 \%$ и $35,27 \pm 3,5 \%$; $\mathrm{p}<0,05)$ оказался выше, чем в сравниваемых городах $(9,67 \pm 2,5 \%$ и 22,07 $\pm 2,9$ и $8,6 \pm 1,6$ и $16,97 \pm 1,7)$. При сравнении психотических психических расстройств и пограничных психических состояний это различие сохраняется только с Петропавловском-Камчатским $(23,17 \pm 2,4 \%$ и $14,07 \pm 0,9 ; \mathrm{p}<0,05)$.

Некоторые методические принципы изучения приживаемости новоселов в городских поселениях изложены в монографии Ж.А. Зайончковской (1972) [19], основанные на изучении этого процесса во многих типичных городах Сибири. Нельзя рассматривать мигрантов в качестве однородной совокупности, необходимо учитывать продолжительность проживания их на новом месте. Приживаемость может характеризоваться средним числом лет, прожитых в месте вселения новоселов. При изучении этой характеристики миграционного процесса нами использовался когортный метод. Когорты состояли из числа мигрантов одних и тех же дат вселения, охватывающих трехлетний период, и находившихся на диспансерном учете к моменту исследования.

Динамика численности когорт при всех психических заболеваниях в Сургуте отличается от аналогичных параметров двух других сравниваемых популяций. В частности тем, что по длительности проживания здесь мигранты имеют менее продолжительную давность вселения. Причем прожившие 4-6 лет составляют 23,4\%, далее эта величина сокращается: проживших 7-8 лет - 19,3\%, 10-12 лет - 14,6\%. В общей сложности мигранты, приехавшие в Сургут за 12 лет до момента обследования, составили $76 \%$ от всей популяции психически больных в этом городе. Направленность изменений численности когорт в Кызыле и Петропавловске-Камчатском в общем аналогичная, так как колебания этого показателя относительно незначительны. Однако следует заметить, что численность когорт после 12-летнего периода проживания во всех городах оказывается сходной до 20-24-летней отметки. 
Так, более 25 лет в Сургуте прожило всего $3,3 \%$ больных, в то время как в Петропавловске-Камчатском $(37,2 \%)$ и Кызыле $(23,3 \%)$ численность этих больных была намного выше. Приведенная динамика численности когорт состоящих на учете по поводу всех психических заболеваний, сгруппированных по трехлетним срокам прибытия, показывает, что в стадии формирования города (на примере Сургута) численность когорт убывает от менее продолжительных сроков к более длительным периодам. В стадии сформировавшегося города (Петропавловск-Камчатский) размеры когорт достаточно устойчивы и происходит накопление больных, имеющих более чем 25-летний период жизни в данном городе (табл. 1).

Т а б л и ц а 1

Динамика охвата диспансерным наблюдением мигрантов различных сроков вселения

\begin{tabular}{|l|c|c|c|c|c|c|}
\hline \multirow{2}{*}{$\begin{array}{c}\text { Количество прожитых } \\
\text { лет после миграции }\end{array}$} & \multicolumn{2}{|c|}{ Сургут } & \multicolumn{2}{c|}{ Кызыл } & \multicolumn{2}{c|}{ Петропавловск-Камчатский } \\
\cline { 2 - 7 } & $\%$ & Абс. & $\%$ & Абс. & Абс. \\
\hline Взяты на учет в год прибытия & 6,0 & 35 & 6,5 & 25 & 5,8 & 64 \\
\hline 1 год & 12,0 & 70 & 9,6 & 37 & 6,0 & 65 \\
\hline 2 года & 11,5 & 67 & 7,8 & 30 & 4,0 & 44 \\
\hline «Новосёлы» & 29,5 & 172 & 23,8 & 92 & 15,7 & 173 \\
\hline От 3 до 5 лет & 24,3 & 142 & 14,5 & 56 & 13,8 & 152 \\
\hline От 6 до 10 лет & 29,7 & 174 & 18,1 & 70 & 17,4 & 191 \\
\hline Свыше 10 лет & 16,4 & 96 & 43,5 & 168 & 53,1 & 584 \\
\hline «Старожилы» & 70,5 & 412 & 76,2 & 294 & 84,3 & 927 \\
\hline \multicolumn{1}{|c|}{ Итого } & 100 & 584 & 100 & 386 & 100 & 1100 \\
\hline \multicolumn{2}{|r|}{} & & & &
\end{tabular}

Численность когорт по отдельным нозологическим группам в целом с определенной степенью сходства повторяет вышеприведенное распределение мигрантов по длительности их проживания, хотя и с некоторыми весьма несущественными особенностями, не вносящими в картину этого распределения значимых корректив. Так, при психотических психических расстройствах удельный вес когорт менее разнится, чем при шизофрении. Кроме того, величина когорт больных шизофренией в отдельных городах в первых временных интервалах (до 12 лет) имеет больший размах колебаний, который в дальнейшем сглаживается (13-24 года). Однако во всех нозологических группах с увеличением длительности проживания величина когорт стабилизируется при значительном числе старожилов, проживающих более 25 лет: в Кызыле - 28,8\% и 52,1\%, в Петропавловске-Камчатском $-22,0 \%$ и $28,7 \%$. При непсихотических психических расстройствах характер распределения когорт в Кызыле и Петропавловске-Камчатском статистически равноценный, а сближение с ними величины когорт в Сургуте происходит в более ранние временные интервалы - 6-8 лет, т.е. накопление больных пограничными психическими состояниями стабилизируется через 7-9 лет во всех городских популяциях.

Величины когорт при умственной отсталости подвержены большим колебаниям, чем когорты других нозологических групп. В Петропавловске-Камчатском для них сохраняется общая закономерность накопления больных, проживающих более 25 лет, тогда как в Кызыле эта тенденция утрачена, а в Сургуте количество длительно проживающих больных с умственной отсталостью линейно сокращается.

\section{ЗАКЛЮЧЕНИЕ}

Анализ когорт мигрантов по их продолжительности проживания в городах вне зависимости от времени начала заболевания и установления диспансерного наблюдения показал, что относительная величина когорт при всех психических заболеваниях зависит от фазы формирования города. Так, в Сургуте на этапе начального развития города величина когорт с непродолжительными сроками проживания больше, чем в Кызыле и ПетропавловскеКамчатском (фаза сформировавшегося города), где величины когорт имеют большую схожесть во всех временных интервалах с накоплением больных с более чем 25-летним проживанием после приезда. Характерная направленность когорт сохраняется и при вычленении нозологических групп. Идентичность в Кызыле и Петропавловске-Камчатском проявляется как при психозах, так и при пограничных психических состояниях, равно как и их отличие от динамики величины когорт в Сургуте, где эта разница более выражена только в когортах лиц, имеющих сроки проживания более 12 лет. В дальнейшем величина когорт в этом городе становится сходной с объемами когорт в других городах. На длительность проживания мигрантов в городах не оказывает влияния наличие (либо 
проявление) у них психического расстройства. В то же время сроки проживания являются отражением, с одной стороны, динамики психических заболеваний, а с другой - фазы формирования города как демографической структуры.

Естественно, что приживаемость мигрантов, в том числе и при наличии у них психических расстройств различного регистра, длительность их проживания в местах вселения является следствием их приспособления - адаптации к изменившимся условиям их существования. Следовательно, есть основания эти понятия рассматривать в диалектическом единстве.

\section{КОНФЛИКТ ИНТЕРЕСОВ}

Авторы заявляют об отсутствии возможных конфликтов интересов в связи с публикацией данной статьи.

\section{ИСТОЧНИК ФИНАНСИРОВАНИЯ}

Работа выполнена в рамках темы основного плана НИР «Распространенность, клиникопатобиологические закономерности формирования и патоморфоза психических и поведенческих расстройств, вызванных употреблением психоактивных веществ в социально-организованных популяциях (профилактический, реабилитационный аспекты)». Номер госрегистрации ААA-А15-115123110064-5.

\section{СООТВЕТСТВИЕ ПРИНЦИПАМ ЭТИКИ}

Работа соответствует этическим стандартам Хельсинской декларации ВМА и одобрена этическим комитетом НИИ психического здоровья Томского НИМЦ (протокол № 53 от 1 октября 2012 г.).

\section{ЛИТЕРАТУРА}

1. Семке В.Я. Производственная миграция и психическое здоровье. Сибирский вестник психиатрии и наркологии. 2012; 2 (71): 5-6.

2. Артемьев И.А. Миграция как источник рынка здоровья. Медико-социальные аспекты охраны психического здоровья: 1-й симпозиум «Больной и общество». Томск, 1991: 4-6.

3. Казначеев В.П. Современные аспекты адаптации. М.: Наука, 1980: 192.

4. Казначеев В.П. Здоровье нации, культура, футурология XXI века. Сборник статей и докладов В.П. Казначеева (2007-2012 гг.). / Под общей редакцией д.м.н. А.В. Трофимова. Составители Ромм В.В., Чиркова С.В. Новосибирск: ЗападноСибирское отделение международной славянской академии наук, образования, искусств и культуры, 2012: 386.

5. Lucken K. Immigrants, Adaptation / Book Editor(s) George Ritzer First published: 29 February 2012 https://doi.org/10.1002/9780470670590.wbeog287.
6. Овчинников А.А., Султанова А.Н., Лазурина А.С., Сычева Т.Ю. Особенности социальнопсихологической адаптации мигрантов (литературный обзор). Сибирский вестник психиатрии и наркологии. 2018; 1 (98): 89-96. https://doi.org/10.26617/1810-3111-2018-1(98)-8996

7. Киселева Л.Т., Овчинников А.А., Султанова А.Н. Особенности эмоционального реагирования мигрантов как фактор, снижающий успешность адаптации. Сибирский вестник психиатрии и наркологии. 2016; 1 (90): 9-15.

8. Бохан Н.А., Овчинников А.А., Султанова А.Н. Аддиктивные расстройства у мигрантов при аккультурации в российское общество. Сибирский вестник психиатрии и наркологии. 2016; 4 (93): 98-105.

9. Rudmin F. Constructs, measurements and models of acculturation and acculturative stress. Int. J. Intercult. Relat. 2009; 33 (2): 106-123. DOI: 10.1016/j.ijintrel.2008.12.001

10. Berry J.W. A psychology of immigration. Journal of Social Issues. 2001; 57 (3): 615-631.

11. Ward C. Acculturation / in D. Landis and R.S. Bhagat (eds.) Handbook of Intercultural Training (2nd ed). Sage Publications, Thousand Oaks, California 1996: 24-147.

12. Bourque F., Van der Ven E., Malla A. A metaanalysis of the risk for psychotic disorders among first- and second-generation immigrants. Psychol. Med. 2011; 41 (5): 897-910. doi: 10.1017/S0033291710001406. Epub 2010 Jul 21

13. Cantor-Graae E., Selten J.-P. Schizophrenia and migration: a meta-analysis and review. Am. J. Psy$\begin{array}{llll}\text { chiatry. } \quad 2005 ; & 162 \quad \text { (1): } & 12-24\end{array}$ https://doi.org/10.1176/appi.ajp.162.1.12

14. DeVylder J.E., Ben-David S., Schobel S.A., Kimhy D., Malaspina D., Corcoran C.M. Temporal association of stress sensitivity and symptoms in individuals at clinical high risk for psychosis. Psychol. Med. $\quad 2013$; 43 (2): $259-68$. https://doi.org/10.1017/S0033291712001262

15. Переведенцев В.И. Методы изучения миграции населения. М. : Наука, 1985: 231.

16. Алаев Э.Б. Социально-экономическая география: Понятийно-терминологический словарь. М.: Изд-во Мысль, 1983: 350.

17. Кокарев Е.М. Социальное развитие северного региона. Магадан, 1981: 70-71.

18. Рыбаковский Л.Л. Население Дальнего Востока за 150 лет. М. : Наука, 1990: 168.

19. Зайончковская Ж.А. Демографическая ситуация и расселение. М.: Наука, 1991: 132.

Поступила в редакцию 19.09.2018 Утверждена к печати 18.02.2019 
Артемьев Игорь Андреевич, доктор медицинских наук, ведущий научный сотрудник отделения аддиктивных состояний.

Владимирова Светлана Владимировна, переводчик отдела координации научных исследований.

Артемьев Игорь Андреевич, igor.artemev.39@mail.ru

УДК 616.89-008.1:2-486.3:331.556:351.778:364-785.14

For citation: Artemyev I.A., Vladimirova S.V. Adaptation and acclimation of migrants with mental disorders - dialectical unity. Siberian Herald of Psychiatry and Addiction Psychiatry. 2019; 1 (102): 99-107. https://doi.org/10.26617/1810-3111-2019-1(102)-99-107

\section{Adaptation and acclimation of migrants with mental disorders - dialectical unity}

\section{Artemyev I.A., Vladimirova S.V.}

Mental Health Research Institute, Tomsk National Research Medical Center, Russian Academy of Sciences Aleutskaya Street 4, 634014, Tomsk, Russian Federation

\section{ABSTRACT}

Various functions of migration are considered, medical paradigm of population's migration is postulated as a directed flow of health owing to which acquisition of new territories and development of already formed manufactures occur. The role and place of adaptive processes in migrants with mental disorders is identified, it is stated that acclimation of migrants in places of their settlement is in a dialectical unity with their adaptation.

Keywords: migration of population, mental disorders, adaptation, acclimation, dialectical unity.

\section{REFERENCES}

1. Semke V.Ya. Proizvodstvennaya migraciya i psihicheskoe zdorov'e [Industrial migration and mental health]. Sibirskij vestnik psihiatrii $i$ narkologii - Siberian Herald of Psychiatry and Addiction Psychiatry. 2012; 2 (71): 5-6 (in Russian).

2. Artemyev I.A. Migraciya kak istochnik rynka zdorov'ya. Mediko-social'nye aspekty ohrany psihicheskogo zdorov'ya: Pervyj simpozium "Bol'noj i obshchestvo" [Migration as a source of health market]. Medical and social aspects of mental health: the first Symposium "Patient and society". Tomsk, 1991: 4-6 (in Russian).

3. Kaznacheev V.P. Sovremennye aspekty adaptacii [Modern aspects of adaptation]. Moscow: Science Publishing House, 1980: 192 (in Russian).

4. Kaznacheev V.P. Zdorov'e nacii, kul'tura, futurologiya XXI veka. Sbornik statej i dokladov V.P. Kaznacheeva (2007-2012 gg.) / Pod obshchej redakciej d.m.n. A.V. Trofimova. Sostaviteli Romm V.V., Chirkova S.V. [Health of the nation, culture, futurology of the XXI century. Collection of articles and reports of V.P. Kaznacheev (2007-2012) / Under the General editorship of doctor of medical Sciences A.V. Trofimov. Compilers of Romm V.V., Chirkova S.V.] Novosibirsk: West Siberian Branch of the International Slavic Academy of Sciences, Education, Arts and Culture, 2012: 386 (in Russian).

5. Lucken K. Immigrants, Adaptation / Book Editor(s) George Ritzer First published: 29 February 2012 https://doi.org/10.1002/9780470670590.wbeog287.

6. Ovchinnikov A.A., Sultanova A.N., Lazurina A.S.,
Sycheva T.Yu. Osobennosti social'nopsihologicheskoj adaptacii migrantov (literaturnyj obzor) [Peculiarities of social-psychological adaptation of migrants (literature review)]. Sibirskij vestnik psihiatrii i narkologii - Siberian Herald of Psychiatry and Addiction Psychiatry. 2018; 1 (98): 89-96. https://doi.org/10.26617/1810-3111-20181(98)-89-96 (in Russian)

7. Kisileva L.T., Ovchinnikov A.A., Sultanova A.N. Osobennosti ehmocional'nogo reagirovaniya migrantov kak faktor, snizhayushchij uspeshnost' adaptacii [Features of emotional response of migrants as a factor for successful adaptation]. Sibirskij vestnik psihiatrii $i$ narkologii - Siberian Herald of Psychiatry and Addiction Psychiatry. 2016; 1 (90): 9-15 (in Russian).

8. Bokhan N.A., Ovchinnikov A.A., Sultanova A.N. Addiktivnye rasstrojstva u migrantov pri akkul'turacii v rossijskoe obshchestvo [Addictive disorders in migrants under acculturation in Russian society]. Sibirskij vestnik psihiatrii $i$ narkologii Siberian Herald of Psychiatry and Addiction Psychiatry. 2016; 4 (93): 98-105 (in Russian).

9. Rudmin F. Constructs, measurements and models of acculturation and acculturative stress. Int. J. Intercult. Relat. 2009; 33 (2): 106-123. DOI: 10.1016/j.ijintrel.2008.12.001

10. Berry J.W. A psychology of immigration. Journal of Social Issues. 2001; 57 (3): 615-631.

11. Ward C. Acculturation / in D. Landis and R.S. Bhagat (eds.) Handbook of Intercultural Training (2nd ed). Sage Publications, Thousand Oaks, California 1996: 24-147. 
12. Bourque F., Van der Ven E., Malla A. A metaanalysis of the risk for psychotic disorders among first- and second-generation immigrants. Psychol. Med. 2011; 41 (5): 897-910. doi: 10.1017/S0033291710001406. Epub 2010 Jul 21

13. Cantor-Graae E., Selten J.-P. Schizophrenia and migration: a meta-analysis and review. Am. J. Psy$\begin{array}{lllll}\text { chiatry. } \quad 2005 ; & 162 \quad \text { (1): } & 12-24 .\end{array}$ https://doi.org/10.1176/appi.ajp.162.1.12

14. DeVylder J.E., Ben-David S., Schobel S.A., Kimhy D., Malaspina D., Corcoran C.M. Temporal association of stress sensitivity and symptoms in individuals at clinical high risk for psychosis. Psychol. Med. 2013; $43 \quad$ (2): 259-68. https://doi.org/10.1017/S0033291712001262

15. Perevedentsev V.I. Metody izucheniya migracii naseleniya [Methods of studying population migration]. Moscow: Science Publishing House, 1985: 231(in Russian).
16. Alaev E.B. Social'no-ehkonomicheskaya geografiya: Ponyatijno-terminologicheskij slovar' [Socioeconomic geography: Conceptual and terminological dictionary]. Moscow: Publishing House of Thought, 1983: 350 (in Russian).

17. Kokarev E.M. Social'noe razvitie severnogo regiona [Social development of the Northern region]. Magadan, 1981: 70-71 (in Russian).

18. Rybakovsky L.L. Naselenie Dal'nego Vostoka za 150 let [Population of the Far East for 150 years]. Moscow: Science Publishing House, 1990: 168 (in Russian).

19. Zayonchkovskaya Zh.A. Demograficheskaya situaciya i rasselenie [Demographic situation and resettlement]. Moscow: Science Publishing House, 1991: 132 (in Russian).

Received September 19.2018 Accepted February 18.2019

Artemyev Igor A., MD, lead researcher of the Department of Addictive States, Mental Health Research Institute, Tomsk National Research Medical Center, Russian Academy of Sciences, Tomsk, Russian Federation. Vladimirova Svetlana V., translator of the Department of Coordination of Scientific Research, Mental Health Research Institute, Tomsk National Research Medical Center, Russian Academy of Sciences, Tomsk, Russian Federation.

Artemyev Igor A., igor.artemev.39@mail.ru 